\title{
Market approval for drugs in the EU: time to change direction?
}

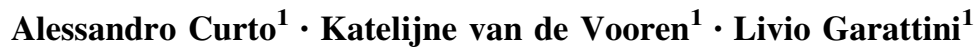

Published online: 27 December 2016

(c) Springer-Verlag Berlin Heidelberg 2016

\section{Introduction}

Since 1995, the European Medicines Agency (EMA) ${ }^{1}$ has been the European Union (EU) authority responsible for assessing the efficacy, safety and quality of all medicines on the entire European market (around 500 million inhabitants) [1]. Set up in London to harmonise the work of the national regulatory authorities (NRAs) for pharmaceuticals, the EMA serves 28 EU Member States at present, as well as the three countries (Iceland, Liechtenstein and Norway) included in the European Economic Area (EEA).

Since by law the EMA can only be based in a EU Member State, the result of the recent British referendum to leave the Union creates an unprecedented situation. Although the EMA recently claimed [2] that this will not affect its procedures and work-streams at all, given the current political and economic crisis in the EU, it is hard to imagine that any such move will merely change only the EMA's postcode.

Here, we analyse the present organisation of the EMA and its network of NRAs to explore future prospects for a new European pharmaceutical regulatory policy. Since it has become common practice for EU public authorities to publish annual reports online for the sake of transparency, we conducted a web-based search to summarise the main features of the EMA and the NRAs of the five major Western EU countries: ${ }^{2}$ Germany, France, Italy, Spain and the Netherlands.

Livio Garattini

livio.garattini@marionegri.it

1 CESAV, Centre for Health Economics, IRCCS Institute for Pharmacological Research 'Mario Negri', Via Camozzi 3 c/o Villa Camozzi, 24020 Ranica, BG, Italy

\section{European medicines agency}

Unlike executive agencies, which the European Commission (EC) creates for a fixed term to manage specific European programs, the EMA is a decentralised agency that operates as an autonomous technical organisation at the heart of a network of 34 NRAs, at least one for each country belonging to the $\mathrm{EEA}^{3}[3]$; this makes the EU pharmaceutical system unique in the world.

The agency is governed by a Management Board of 40 members appointed for a 3-year (renewable) term, comprising a chairman, one representative for each of the 28 EU Member States, two for the EC and the European Parliament, two for patients' and doctors' associations, and one observer (without voting rights) each for the three further EEA countries ${ }^{4}$ [4]. The Management Board sets the yearly budget and approves the annual working program proposed by the Executive Director.

EMA carries out its scientific and technical assessments through seven scientific committees, whose members are mainly appointed by each NRA for a 3-year (renewable)

\footnotetext{
${ }^{1}$ Originally called (until 2004) the European Agency for the Evaluation of Medicinal Products (EMEA).

${ }^{2}$ We deliberately excluded the UK from the basket of countries in the light of the recent referendum result. Information was retrieved from authorities' websites and related official documents. All data refer to the latest available years (2014 or 2015).

${ }^{3}$ Germany, the Netherlands and Poland are the only three nations that indicated two authorities as counterparts for EMA. The second German agency, the Paul-Ehrlich-Institut (PEI), refers to the EMA only for vaccines and biomedicines, while the second Dutch authority is a branch of the Ministry of Health, Welfare and Sport in charge for manufacturing inspections and controls.

4 The representatives of the European countries, the EC and the European Parliament are appointed directly by their institutions, and the remaining five 'lay members' are appointed by the EU Council.
} 
period [5]. For marketing authorisations, the Committee for Medicinal Products for Human Use (CHMP) [6] nominates a member to lead each scientific assessment, referred to as 'rapporteur', and another member ('co-rapporteur') as an independent control. Both are backed by assessment teams to provide the necessary expertise, and the EMA remunerates the selected NRAs for these tasks carried out on its behalf. Any interference from industry is formally forbidden; however, the selection of 'rapporteurs' and/or 'corapporteurs' can be indirectly influenced by applicants' previous choices (e.g., in the setting of clinical trials).

The CHMP usually adopts scientific recommendations by consensus in plenary meetings [6]. If no full consensus can be reached, the committee agrees on a final position based on a majority vote, and divergent opinions are made publicly available. The working language is English, although many types of documents are translated in all the EU languages (e.g., the European public assessment reports).

The EMA staff has risen steadily, from 103 employees at the beginning to 775 at present [7], for a total budget of $€ 304$ million in 2015 [8] (Table 1). Most EMA revenues come from industry through regulatory fees-a much higher proportion than that of other big regulatory authorities in the world (e.g., $83 \%$ of the total budget in 2015 vs. 45\% for the American Food and Drug Administration) [9]. Although the EMA is one of the most labor intensive EU agencies [10], personnel costs accounted only for $35 \%$ of the total expenditure, slightly less than the payments to NRAs for services (40\% of the total expenditure) - the major cost item of the budget. However, the estimated gross average wage was very high, around $€ 134,000$ on a yearly basis.

\section{National regulatory authorities}

France, Germany and the Netherlands established the present NRAs for pharmaceuticals before EMA, while Spain and Italy introduced a single national agency after 1995 (respectively in 1999 and 2003) (Table 1). All the NRAs surveyed have a common frame of activities (e.g. marketing authorisation, post-marketing surveillance, inspections and controls, promotion of independent research and information). The Italian AIFA (Agenzia Italiana del Farmaco) and the Dutch CBG (College ter Beoordeling van Geneesmiddelen) are also responsible, respectively, for pricing and reimbursement (P\&R), and the assessment of botanicals and novel foods.

The formally employed staff is at least double in the German BfArM (Bundesinstitut für Arzneimittel und Medizinprodukte) [11] and the French ANSM (Agence Nationale de Sécurité du Médicament et des produits de santé) [12]; of the other three agencies surveyed, the Italian AIFA [13] has a yearly budget double that of the Spanish AEMPS (Agencia Española de Medicamentos y Productos Sanitarios) [14] and the Dutch CBG [15], with by far the lowest proportion of personnel expenses in the yearly budget. The estimated yearly gross average wages are somewhat higher in the French and Dutch agencies, though still much lower than the estimate for EMA.

Table 1 Main figures of the European Medicines Agency (EMA) and the major European Union (EU) Western Agencies for pharmaceuticals

\begin{tabular}{|c|c|c|c|c|c|c|}
\hline & EU & France & Germany & Italy & Spain & The Netherlands \\
\hline Regulatory authority & EMA & ANSM & BfArM & AIFA & AEMPS & CBG \\
\hline Year of foundation & 1995 & $1993^{\mathrm{a}}$ & 1994 & 2003 & $1999^{\mathrm{b}}$ & 1963 \\
\hline Annual budget $(\mathrm{M} €)$ & 304 & 139 & 84 & 95 & 47 & 40 \\
\hline Personnel (FTE) & 775 & 1005 & 1100 & 399 & 484 & 288 \\
\hline Estimated gross average wage $(\mathrm{K} €)^{\mathrm{c}}$ & 134 & 79 & 53 & 58 & 47 & 74 \\
\hline Personnel costs on the yearly budget (\%) & 35 & 57 & 69 & 23 & 48 & 59 \\
\hline Revenues by EMA on the yearly budget (\%) & - & 6 & 5 & 4 & 6 & 14 \\
\hline CHMP rapporteurships $(n)$ & - & 6 & $13^{\mathrm{d}}$ & 0 & 4 & 13 \\
\hline CHMP co-rapporteurships $(n)$ & - & 6 & $12^{\mathrm{c}}$ & 10 & 12 & 8 \\
\hline
\end{tabular}

ANSM Agence nationale de sécurité du médicament et des produits de santé, AEMPS Agencia Española de Medicamentos y Productos Sanitarios, AIFA Agenzia Italiana del Farmaco, BfArM Bundesinstitut für Arzneimittel und Medizinprodukte, CBG College ter Beoordeling van Geneesmiddelen, CHMP Committee for Medicinal Products for Human Use, EEA European Economic Area, FTE Full Time Equivalent, $K$ thousands, $M$ millions

${ }^{a}$ From 1999 to 2012 Agence française de sécurité sanitaire des produits de santé (Afssaps)

b From 1999 to 2002 Agencia Española del Medicamento (AEM)

c Total personnel costs/total number of full time equivalent employees

${ }^{\mathrm{d}}$ Including the (co)rapporteurships conducted by the second agency (the Paul-Ehrlich-Institut) 
Broadly, our sample of agencies covered one-third of the CHMP (co)rapporteurships required by EMA in 2015. While the Italian AIFA never served as CHMP 'rapporteur' during the last year, the Dutch CBG held it as often as German NRAs (including the second agency) [1]. This might partly explain why the Dutch CBG earned $14 \%$ of its annual budget from services to EMA, while the range was only from $4 \%$ to $6 \%$ in the other NRAs.

\section{Discussion}

Some observers consider the EMA a success [16], as it has enhanced harmonisation by fostering a homogeneous regulatory policy throughout the EU. These positive comments illustrate EMA's contribution to optimising the assessment process and the use of human resources and expertise devoted to the same objective, saving efforts and financial resources for the EU Member States and the pharmaceutical industry as well.

However, in the light of our survey, we wonder whether the EMA 'spillover' in terms of efficiency can be necessarily taken as positive in an overall European perspective. Our findings suggest that the EU Member States, fearing a loss of sovereignty in a common pharmaceutical market, hampered the EU Commission's original liberalisation design, leading to a 'hub and spokes' model, where NRAs still play a major role despite the EMA's pivotal position in the new EU pharmaceutical regulatory system [16]. The EMA has seemed to act so far as a highly specialised secretariat with well-paid employees, which commits the NRAs to conducting scientific and technical tasks on its behalf [17].

The EU regulatory network consists of NRAs that are each still responsible in their own country, and now provide technical and scientific expertise to EMA too in many cases. This contribution is very uneven, however, and does not seem to be related to the size of the country [16]. For instance, the Swedish and Austrian RNAs are often involved as CHMP 'rapporteurs' (respectively, 25 and 12 times in 2015) [1]. As confirmed by our survey, the older and better structured RNAs candidate themselves more often and are more likely to be appointed 'rapporteurs'. These countries could also be the best candidates for hosting the new EMA site but such a choice could widen the gap with the Eastern agencies that have joined the network more recently.

Moreover, in these two decades the number of EMA employees has steeply increased and other sizeable national agencies for Health Technology Assessment (HTA) and P\&R have been established, e.g., HAS (Haute Autorité de Santé) in France and IQWiG (Institut für
Qualität und Wirtschaftlichkeit im Gesundheitswesen) in Germany, with 400 and 185 employees and yearly budgets of $€ 51$ million and 19 million, respectively, in 2015. Since the EMA still has no institutional role after market approval, and its present strategy is to limit further its scope to preliminary assessment of the efficacy and safety of drugs (thus helping companies avoid having to conduct 'head-to-head' clinical trials) [18], the whole assessment of comparative efficacy and cost-effectiveness for domestic $\mathrm{P} \& \mathrm{R}$ has increased dramatically the burden of regulatory affairs at national level.

To sum up, beyond the specific criticisms on the EMA's policy [17], and bearing in mind that a centralised approach (as opposed to a mutual recognition scheme driven by NRAs) was launched as a way to reduce transaction costs and make the drug approval process more efficient and accountable, we wonder whether this duplication of regulatory efforts and costs inside the EU can be really considered a success story.

\section{Future prospects}

In its Roadmap to 2020, the EMA proposed fostering the development of new medicines for real public health needs and optimising the operation of its NRA network as two major goals [19]. We wonder, however, how these can be really achieved without radical changes in the present organisation and strategy. For the first goal, EMA should conduct an ex ante priority-setting study to highlight the 'unmet needs' that really matter in terms of public health, in order to steer the industry's research and development investments in advance towards priority therapeutic areas [20].

Another major step towards the second EMA goal would be to classify new drugs according to their potential innovative content-ideally in just two groups: drugs for diseases that can already be successfully treated, and drugs addressing important 'unmet needs'. This would necessarily imply 'head-to-head' clinical trials for market approvals of most drugs, and would lead to a more reasonable workload for P\&R at national level-exactly the opposite direction from the latest EMA tendency to fasttrack drugs to marketing through the so-called 'adaptive licensing' [18].

In conclusion, if the EMA goes on with its present strategy, fostered by the popular 'political creed' that all new drugs have to be available to patients as soon as possible, regardless of their therapeutic 'added value', we are afraid the EU pharmaceutical regulation will become hard to sustain and govern for most member countries in the near future. 


\section{References}

1. EMA. Annual Report 2015. http://www.ema.europa.eu/docs/en GB/document_library/Annual_report/2016/05/WC500206482. pdf (2015). Accessed 21 Sept 2016

2. EMA. Statement on the outcome of the UK referendum. News 06/07/2016. http://www.ema.europa.eu/ema/index.jsp?curl=pages/ news_and_events/news/2016/07/news_detail_002566.jsp\&mid= WC0b01ac058004d5c1 (2016). Accessed 21 Sept 2016

3. EMA. National competent authorities (human). http://www.ema. europa.eu/ema/index.jsp?curl=pages/medicines/general/general_ content_000155.jsp\&mid=WC0b01ac0580036d63 (2016). Accessed 21 Sept 2016

4. EMA. Rules of procedure of the Management Board. EMA/ MB/115339/2004/en/Rev.6 http://www.ema.europa.eu/docs/en_ GB/document_library/Other/2010/01/WC500038065.pdf (2016). Accessed 17 March 2016

5. EMA. Committees, working parties and other groups. http:// www.ema.europa.eu/ema/index.jsp?curl=pages/about_us/general/ general_content_000217.jsp (2016). Accessed 21 Sept 2016

6. EMA. Committee for medicinal products for human use. Rules of procedure. EMEA/45110/2007 EMEA/MB/87146/2007 http:// www.ema.europa.eu/docs/en_GB/document_library/Other/2009/ 10/WC500004628.pdf (2007). Accessed 21 Sept 2016

7. EMA. Annual Report 1996. http://www.ema.europa.eu/docs/en GB/document_library/Annual_report/2009/12/WC500016813.pdf (1996). Accessed 21 Sept 2016

8. EMA Administration and Corporate Management Division. Annual accounts. Financial year 2015. EMA/281783/2016 http:// www.ema.europa.eu/docs/en_GB/document_library/Report/2016/ 06/WC500209473.pdf (2015). Accessed 21 Sept 2016

9. Department of Health and Human Services. FDA Budget Report Fiscal Year 2016. http://www.fda.gov/downloads/AboutFDA/ ReportsManualsForms/Reports/BudgetReports/UCM432322.pdf (2016). Accessed 21 Sept 2016
10. EU. Analytical Fiche $\mathrm{Nr}^{\circ}$ 23. Staff Policy Plan. http://europa.eu/ european-union/sites/europaeu/files/docs/body/fiche_23_sent_to_ ep_cons_2011-07-20_en.pdf (2010). Accessed 21 Sept 2016

11. German Federal Ministry of Finance. Annual Report 2014-2015. http://www.bfarm.de/SharedDocs/Downloads/EN/BfArM/Pub likationen/Jahresbericht2014-15.pdf?__blob=publicationFile\& $\mathrm{v}=2$ (2015). Accessed 21 Sept 2016

12. Agence Nationale de Sécurité du Médicament et des produits de santé. Annual Report 2014. http://ansm.sante.fr/var/ansm_site/ storage/original/application/ee4fa2afa64ec300a551d912ff7c0559. pdf (2014). Accessed 21 Sept 2016

13. Agenzia Italiana del Farmaco. Annual Balance Sheets. Annual Report 2015. http://www.agenziafarmaco.gov.it/it/content/bilanci (2015). Accessed 21 Sept 2016

14. Agencia Española de Medicamentos y Productos Sanitarios. Annual Report 2015. https://www.aemps.gob.es/en/laAEMPS/ memoria/docs/memoria-2015.pdf (2015). Accessed 21 Sept 2016

15. College ter Beoordeling van Geneesmiddelen. Annual Report 2015. http://2015.cbgjaarverslag.nl/en/ (2015). Accessed 21 Sept 2016

16. Groenleer, M.L.P.: The autonomy of European Union Agencies: a comparative study of institutional development. Delft, Eburon (2009)

17. Garattini, S.: The European medicines agency is still too close to industry. BMJ 353, i2412 (2016). doi:10.1136/bmj.i2412

18. Garattini, L., Curto, A.: European medicines agency: leave the UK but remain the same? J. R. Soc. Med. 109(9), 324-325 (2016). doi:10.1177/0141076816663559

19. EMA. EU Medicines Agencies Network Strategy to 2020. Working together to improve the health. EMA/MB/151414/2015. http://www.ema.europa.eu/docs/en_GB/document_library/Other/ 2015/12/WC500199060.pdf (2015). Accessed 17 Dec 2015

20. Garattini, L., Curto, A., Freemantle, N.: Pharmaceutical price schemes in Europe: time for a 'continental' one? Pharmacoeconomics. 34(5), 423-426 (2016) 